\title{
Super power of antioxidant in oxidative stress and diabetes mellitus
}

\author{
Mariyam S ${ }^{1}$, Jose $\mathrm{J}^{1}$, Kumar $\mathrm{S}^{1}$ and Parmar $\mathrm{MY}^{2 *}$ \\ ${ }^{1}$ Jamia Salafia Pharmacy College, Pulikkal, University of Kerala, Kerala, India \\ ${ }^{2}$ Sanjay College of Pharmacy, Dr A. P. J. Abdul Kalam Technical University, Mathura, UP, India
}

\begin{abstract}
Diabetes mellitus is a group of metabolic disorder characterized by peculiarly high levels of blood glucose due to complete or relative insufficiency of insulin secretion as well as disturbances in carbohydrate, fat and protein metabolism. Increasing indication revealed that oxidative stress plays a main role in the pathogenesis of diabetes mellitus. Free radicals are formed excessively in diabetes by glucose oxidation and non-enzymatic protein glycation. Abnormally high levels of free radicals and the simultaneous decline of antioxidant defense mechanisms can lead to damage of cellular organelles and enzymes increased lipid peroxidation, and development of insulin resistance. This penalty of oxidative stress can promote the development of complications of diabetes mellitus. Antioxidants obtained from nature helps in neutralization of reactive oxygen species and significantly reduce the probability of progression of diabetic complications. A variety of nutritionally important vitamins, supplements and some constituents of natural food sources, including cappers, broccoli, tomatoes, berries, grapes, spinach, carrots, nuts, etc. naturally trim down the injury caused by oxidative stress in diabetes mellitus. The review describes the oxidative stress and super power role of antioxidants role in diabetes mellitus.
\end{abstract}

\section{Introduction}

Diabetes mellitus characterized by elevated blood glucose level is basically a metabolic disorder in which the beta cells of the pancreas produce insufficient insulin [1]. Diabetes mellitus problems vary from one individual to another, but are being determined by on health and patient diet [2]. Globally, about 190 million population having different age groups are affected by diabetes mellitus and is one of the most prominent cause of impairment and death in world [3]. The metabolic theory of diabetes mellitus proposes that complications such as endothelial damage and cellular damage belongs to long term hyperglycemia, while genetic theory propose that diabetes complications are genetically predetermined. In past practices are carried for diabetes control and complications which determine that maintained blood glucose can be very effective [4]. Diabetes mellitus symptoms include polyphagia (increased hunger), polydipsia (increased thirst), polyuria (increase urination). Due to hyperglycemia malfunctioning and dysfunction of various organs such as heart (mainly myocardial infraction), kidneys (diabetic nephropathy), nerves (diabetic neuropathy), eyes (diabetic retinopathy) usually occur [5,6].

\section{Diabetes mellitus and oxidative stress}

Various mitochondrial, enzymatic and non-enzymatic pathways mainly comprise oxidative stress in diabetes mellitus. The imbalance in an antioxidant-prooxidant is due to auto oxidation of glucose level in diabetes usually leads to high energy particle generation. In cells, there usually exists a balance between antioxidants elimination and free radical development. The gradual increase in free radicals and diminishing antioxidant defense mechanism potential is also the fact linking diabetes mellitus with oxidative stress [7].

In the oxidative stress initiated by non-enzymatic sources, free radicals/reactive oxygen species generation is directly increased by hyperglycemic condition. Auto-oxidation of glucose generates hydroxyl radicals. In the non-enzymatic path glucose reacts with proteins which causes improvement in advanced glycation end products and changes protein and cellular/immune function, advanced glycation products bind with their receptor and causes improved cell signaling pathways and reactive oxygen species production during the biological process at multiple steps. Xanthine oxidase, Nitric oxide synthetases and NADPH are enzymes associated with membrane and is importantly played role in the enzyme source of reactive oxygen species in diabetes mellitus. In polyol (sorbitol) pathway the increase glucose metabolism leads to improved production of superoxide radicals. In diabetic patients there occurs association between lipid peroxidation and impaired glucose level.

In diabetic patients elevated level of some pro-oxidants a protein such as ferritin containing $20 \%$ of iron usually found in homocysteine and intestine are the probable sources of oxidative stress. By the peroxidation of arachidonic acid the prostaglandin like compounds F-2 isoprostanes are formed mediated by free radicals. In type 2 diabetic patients levels of F2-isoprostane have been augmented in plasma and urine $[8,9]$.

The mitochondrial respiratory chain also acts as a resource of reactive species through the non-enzymatic mechanism. The process involves the transfer of electrons from electron carriers NADH to FADH2, during oxidative phosphorylation through complex formation in the inner mitochondrial membrane. Research studies also devised

${ }^{\star}$ Correspondence to: Mihir Y. Parmar, Principal and Professor, Pharmacology, Dr A. P. J. Abdul Kalam Technical University, Mathura, UP, India, E-mail: mihirparmar4uonly@yahoo.com

Key words: diabetes mellitus, antioxidants, food sources, free radicals

Received: February 29, 2020; Accepted: March 13, 2020; Published: March 17, 2020 
that in diabetic patients during hyperglycemic condition superoxide is the 1st step of oxidative stress. Normally superoxide molecules are removed immediately by endogenous mechanism. In hyperglycemias condition the endothelial cell triggers increased amount of reactive oxygen species usually superoxide which tends to the development of diabetes disorders [10].

\section{Antioxidants}

Antioxidants are chemical or biological agents able to neutralize the potentially damaging action of free radicals such unstable molecules as peroxyl radical, hydroxyl radical, and singlet oxygen and peroxynitrate radicals. The oxidation process of other macromolecules is avoided or slows down by antioxidants. The destructive effect of free radicals in cells is minimized or terminated by antioxidants. The tissues or cell damage by toxic metabolites is minimized by antioxidants. In humans everyday activities oxidation plays important role as there is antioxidant defence mechanism present such as lycopene, beta carotene, glutathione, flavonoid, selenium natural vitamin such as vitamin E, vitamin A antioxidant enzymes such as catalase peroxidase, glutathione-S-transferase finish the accessibility of peroxidase as hemeprotein, iron, copper ions. In previous studies there is strong relation found between oxidative stress and reactive oxygen species for human disorders/diseases. Antioxidants and free radicals studies are very important in today's research for understanding the relationships of diseases such as cancer, neurodegenerative diseases, diabetes mellitus and cardiac arrest [11].

\section{Antioxidants classification}

Antioxidants may be Synthetic or Natural. Synthetic Antioxidants; The phenolic group compounds are included in synthetic antioxidants and these finish the oxidative stress, free radicals and various biological reactions associated with the free radical negative effect. e.g.; Nordihydroguaiaretic acid (NDGA), esters of gallic acid (propyl gallate), tertiary butyl hydroquinone (TBHQ), butylated hydroxyl anisole (BHA) and butylated hydroxyl toluene (BHT).

\section{Natural antioxidants}

These act on lipid free radicals and break the chain. e.g.: Mineral antioxidants, Vitamins, Phytochemicals [12].

\section{Origin and sources of antioxidants}

In colored fruits Beta carotene is the most biologically active antioxidants like squash, potatoes, apricots, pumpkin, mangoes and orange. Natural food, leafy vegetables and fruit sources are the richest source of antioxidants. Besides this lemon, amla, ashwagandha also contains antioxidants. Beta carotene is also found in green leafy vegetables such as spinach, kale, and coloured greens. For healthy eyes Lutein is best green leafy vegetable.

In most of developing countries wheat and rice are the main dietary source of selenium having major antioxidant enzymes. Carrots, milk, sweet potatoes, mozzarella and egg yolks consist retinol, 3 hydroxyretinol and didehydroretinol. Poultry, beef, cereals and fish contains vitamin C.

Flavonoids, diterpenes, cinnamic acid, phenylpropanoids contains phytoconstituents with antioxidants. In wheat germ oil, corn oil, mangoes, almonds, nuts contains vitamin E. Higher plants contain natural antioxidants in leaves, pods, roots, seeds, pollen, wood and bark. Treatment of severe diseases with oxidative stress is possibly cured by plants antioxidants including diabetic mellitus [13-16].

\section{Plasma antioxidant potential}

In humans Plasma contains antioxidants and use as a marker to measure oxidative stress. There are many compounds present in plasma, which protect cell and cellular biomolecules from oxidative stress. So the combined action of all molecules in plasma represents the antioxidant capacity of plasma $[17,18]$. The plasma glycemic level will be low in diabetic patients than healthy ones because the antioxidants are present in low amount in diabetic patient plasma [19,20].

The increase in oxidative stress while decrease of antioxidant capacity correlated with complications of diabetes mellitus as insulin resistance and DNA damage [21]. Due to low antioxidant defense in plasma the problems like blindness, nerve damage, cardiovascular disease and nephropathy occurs [22].

\section{Role of antioxidants in diabetes mellitus}

Antioxidants could be obtained from different dietary sources and is used for maintaining free radicals stable and not to develop oxidative stress thus improving our defence mechanism.

In nature, there are various non-enzymatic and enzymatic mechanisms for removal of reactive oxygen species. In nonenzymatic antioxidant system includes ascorbic acid, retinol, glutathione, carotenoids, tocopherols, and trace elements like selenium, copper, zinc, coenzyme Q10, uric acid, factors of folic acid, riboflavin and thiamine. Vitamin $\mathrm{E}$ is the fat soluble responsible for prevention of lipid peroxidation. Glutathione acts as a scavenger as well as a substrate for glutathione peroxidase. There are eight different forms in vitamin $\mathrm{E}$ exist in the fat soluble form in which A tocopherol is found in sunflower and wheat germ oil and the safflower oil is most active in biological form in humans. Lipid peroxidation is prevented through fat soluble vitamin E. Researchers recently suggested that nitric oxide production in epithelial cells is increased through vitamin C.

In chronic cardiac complications of diabetes patient the important enzymes goes into smooth muscles. So the major organs such heart, kidneys are directly affected by diabetes. In the enzymatic antioxidant defence mechanism SOD and Glutathione reductase is important. Glutathione reductase regenerates glutathione, which can be used as hydrogen donor by glutathione peroxidase through elimination of hydrogen peroxide. SOD converts superoxide to hydrogen peroxide [23-25].

There are various mechanisms in which antioxidant differ in their action mechanism. These are free radicals scavenging mechanism, inhibition of enzymes that humiliate free radical reactions; degradation of proteins, including transferring that can bind metals which eventually stimulate free radicals.

\section{Human health and oxidative stress}

Oxidative stress is a pathological condition triggered by the damaging action on cells and tissues of the body Oxidative is the direct consequence of an increased generation of free radicals and or reduced physiological activity of antioxidant defenses against free radicals and reactive nitrogen species. Non radical species are hydrochlorous acid and hydrogen peroxide molecules. Free radical species are superoxide molecules, hydroperoxyl molecules, hydroxyl molecules. Reactive nitrogen species are having free radicals are nitrogen dioxide and nitric oxide while non-radical are peroxynitrates and peroxynitrites. By the physical, physiological and chemical factors the reactive radicals, nitric oxide peroxynitrite and superoxide molecules cause tissue damage. 
There are a variety of different defense mechanisms by which human body works against oxidative stress induced by free radicals as tissue repair, anticipatory mechanism, physical resistance and antioxidant defense. Reactive oxygen species of various free radicals are involved in cardiovascular diseases, renal disorders, autoimmune disorders, neurodegenerative disorders, peptic ulcer, cataract, lung cancer (Figure 1) $[26,27]$.

\section{Newer therapeutic/preventive approaches through natural antioxidants}

Diabetes mellitus management with no side effect is still a challenge in 21 century for doctors and researchers. In the treatment of diabetes mellitus herbal drugs is of great interest due to low cost, efficiency and less side effects and so a variety of plants are being used as an herbal treatment. In the WHO report about $80 \%$ of the global population are dependent on traditional medicines because of poverty. In herbal treatment phytoconstituents derived from plants are important and includes glycosides, alkaloids, glycopeptides, steroids, hypoglycans, guanidine, carbohydrates, gums, various amino acids and peptidoglycans. The phytoconstituents greatly influence metabolic activities which directly affect glucose level in the body.

For the management of some diseases such as Alzheimer disease, stroke, cardiac arrest, cancer, atherosclerosis and Parkinson disease antioxidant formulation is of great study and effort. Diabetic complications can be reduced by dietary antioxidants and is one of promising therapeutic approach. For the treatment of some diseases such as stroke, atherosclerosis, cancer, neurodegenerative diseases, diabetes mellitus and human ailments (Figure 2) [28-33].

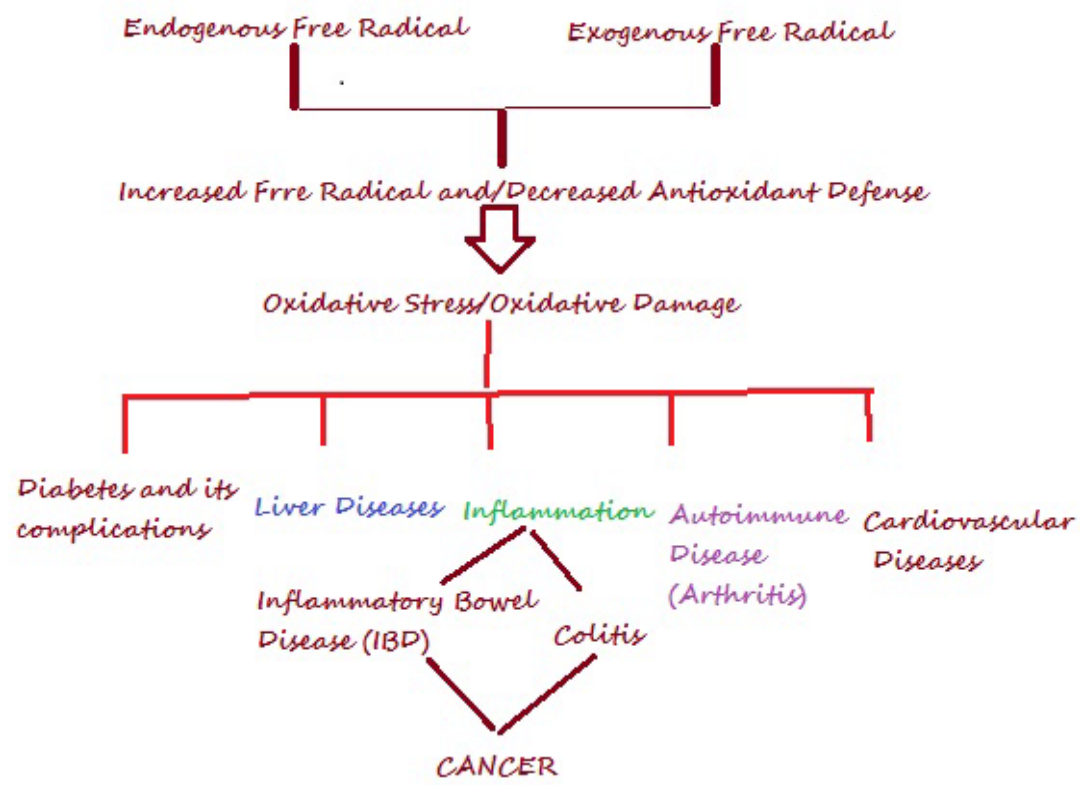

Figure 1. Oxidative stress \& it's consequences

TRADITIONAL MEDICINAL PLANTS<smiles>CC12CC3CC(C1)C(C3)C2</smiles>

BIOLOOGICAL ACTINTTIES

(IN VITRO IN VIVO STUDIES)

\}

ISOLATED EFFECTINE BIOACTINE CONSTTTUENTS FROM SPECIFC ACTNE PLANTS

(Thrw various bioanalytical methods)

\{

Novel Natural Antioxidants

\

TREATMENT FOR VARIOUS FREE RADICAL INDUCED

DISESASES/DISORDER LiKE DIABETES AND ITS COMPLCATTONS

Figure 2. Newer therapeutic/preventive approaches through natural antioxidants 


\section{Conclusion}

In recent studies, it is stated that if a traditional system of medicines like Siddha and Ayurveda is used with modern science medicines will be very effective. Diabetic complications associated with oxidative stress can be minimized to some extent by natural antioxidants. But there is no perfect mechanism developed till to date in which the diabetic complications are known exactly. In various there are various clinical, epidemiological and experimental antioxidants are developed to cure of diabetes and other diseases.

\section{References}

1. Patel V, Chitra V, Prasanna PL, Krishnaraju V (2008) Hypoglycemic effect of aqueous extract of Parthenium hysterophorus L. in normal and alloxan induced diabetic rats. Ind $J$ of Pharmacol 40: 183-185. [Crossref]

2. Chintan AP, Nimish LP, Nayana B, Bhavna M, Mahendra G, et al. (2011) Cardiovascular complication of diabetes mellitus. J Appl Pharm Sci 4: 1-6.

3. Klavin DC (1993) The effect of intensive treatment of diabetes on the development and progression of long-term complications in insulin-dependent diabetes mellitus. $N$ Engl J Med 329: 977-986.

4. Wild SH, Roglic G, Green A, Sicree R, King H (2004) Global prevalence of diabetes: estimates for the year 2000 and projections for 2030. Diabetes Care 27: 1047-1053. [Crossref]

5. Alteras I, Saryt E (1979) Prevalence of pathogenic fungi in diabetic patent. Mycopathologia 67: 157-159.

6. Rabini RA, Fumelli P, Galassi R (1994) Increased susceptibility to lipid oxidation of low-density lipoproteins and erythrocyte membranes from diabetic patients. Metab Clin Exp 43: 1470-1474.

7. Dandu AM, Inamdar NM (2009) Evaluation of beneficial effect of antioxidant properties of some plants in diabetic rats. Pak J of pharma Sci 22: 49-52.

8. Davies KJ (1997) Protein damage and degradation by oxygen radicals: IV, Degradation of denatured protein, J BiolChem 262: 9914-9920.

9. Valko M, Leibfritz D, Moncol J, Cronin MD, Mazur M (2007) Free radicals and antioxidants in normal physiological functions and human disease. Int $\mathrm{J}$ Biochem Cell Biol 39: 44-84.

10. Kowluru RA, Chan PS (2009) Oxidative stress and diabetic retinopathy. Exp Diabetes Res 4: 436-473.

11. Agnieszka P, Dorota R, Iren A, Maciej J, Stefan A (2011) High Glucose concentration affects the oxidant-antioxidant balance in cultured mouse podocytes. $J$ Cell Biochem 112: $1661-1672$

12. Wolff SP (1993) Diabetes mellitus and free radicals: free radicals, transition metals and oxidative stress in the etiology of diabetes mellitus and complications. Br MedBull 49: 642-645.

13. Rane R, Gangollia D, Patil S, Ingawale K (2012) Amla, Ashwagandha and Shatavari formulations as herbal medicines and nutraceuticals. Res J Pharmaceutical Sci 1: 10-15.

14. Lee SC, Chang WJ, Lu KT, Lo D, Wu MC (2013) Antioxidant capacity and hepatoprotective effect on ethanol-injured liver cell of lemon juice concentrates and its comparison with commercial Japanese apricot juice concentrates. Res J Pharmaceutical Sci 2: 7-14.
15. Ha H, Kim KH (1999) Pathogenesis of diabetic nephropathy: the role of oxidative stress and protein kinase C. Diabetes Res Clin Pract 45: 147-151.

16. Nordberg J, Arnér EJ (2008) Reactive oxygen species, antioxidants, and the mammalian thioredoxin system. Free Radic Biol \& Medic 1: 1287-1312.

17. Nishikawa T, Edelstein DD, Yamagishi S, Matsumura T, Kaneda Y, et al. (2004) Normalizing mitochondrial superoxide production blocks three pathways of hyperglycemic damage. Nature 404: 787-90.

18. Ahsan H, Ali A, Ali R (2003) Oxygen free radicals and systemic autoimmunity. Clin Exp Immunol 31: 398-404.

19. Waris G, Alam K (1998) Attenuated antigenicity of ribonucleoproteins modified by reactive oxygen species. Biochem Molec Biol Int 45: 33-45.

20. Bylka W, Matlawaska I (2007) Natural flavonoids as antimicrobial agents. The $J$ of American Nutraceutical Association 7: 24-31.

21. Chikezie PC, Monago CC (2004) Glutathione s-transferase activity in rats. African J of Biochemistry research 3: 210-214.

22. Hamblin M, Smith HM, Hill MF (2007) Dietary supplementation with vitamin E ameliorates cardiac failure in type 1 diabetic cardiomyopathy by suppressing myocardial generation of 8-iso- prostaglandin F2 and oxidized glutathione. $J$ Cardio 13: 884-892.

23. Rowe L (2009) DNA damage-induced reactive oxygen species: A genotoxic stress response, PhD Thesis, Emory University, Georgia, USA.

24. Tilethe S, Chourasiy PK, Dhakad RS, Kumar D (2013) Potential of Rutin and Vildagliptin combination against alloxan induced diabetic nephropathy in mice. Res $J$ Pharmaceutical Sci 2: 1-7.

25. Mihir Y Parmar (2018) Obesity and type 2 diabetes mellitus. Integrative Obesity and Diabetes 4: 1-2

26. National Diabetes Data Group (1979) Classification and diagnosis of diabetes mellitus and other categories of glucose intolerance. Diabetes 28: 1039-1057. [Crossref]

27. World Health Organization (1980) Report of the Expert Committee on Diabetes. WHO Technical Report Series. no. 646, Geneva, Switzerland.

28. World Health Organization (1985) Diabetes Mellitus, Report of a Study Group. WHO Technical Report Series, no. 727, Geneva, Switzerland.

29. Rizvi SI, Maurya PK (2007) Markers of oxidative stress in erythrocytes during aging in humans. Annals of the New York Academy of Sciences 1100: 373-382.

30. Mihir Y, Parmar, Shravya B (2019) Anti atherosclerotic potential of Echinops Echinatus against high fat diet induced atherosclerosis in wistar rats. Bio Engg Bio Med Sci Int J.

31. Lodovicia M, Giovannellia L, Pitozzia V, Bigaglia E, Bardinib G (2008) Oxidative DNA damage and plasma antioxidant capacity in type 2 diabetic patients with good and poor glycaemic control, Mutation Research 638: 98-102.

32. Hisalkar PJ, Patne AB, Karnik AC, Fawade MM, Mumbare SS (2012) Ferric reducing ability of plasma with lipid peroxidation in type 2 diabetes. International Journal of Pharmacy and Biological Sciences 2: 53-56.

33. Styskal J, van Remmen H, Richardson A, Salmon AB (2012) Oxidative stress and diabetes: what can we learn about insulin resistance from antioxidant mutant mouse models? Free Radical Biology and Medicine 52: 46-58.

Copyright: (C2020 Mariyam S. This is an open-access article distributed under the terms of the Creative Commons Attribution License, which permits unrestricted use, distribution, and reproduction in any medium, provided the original author and source are credited. 